\title{
Coagulação por plasma de argônio como adjuvante à curetagem estendida em tumores de células gigantes do osso: Um estudo de 50
}

casos

\section{Argon Beam Coagulation as an Adjuvant for Extended Curettage for Giant Cell Tumors of the Bone: A Study of 50 Cases}

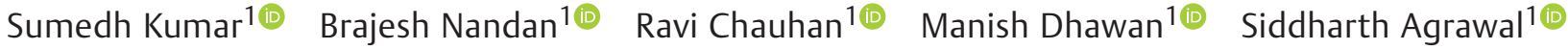 \\ Sijal Rivi ${ }^{10}$ \\ ${ }^{1}$ Departamento de Ortopedia, Sir Ganga Ram Hospital, Nova Delhi, \\ Índia \\ Rev Bras Ortop \\ Endereço para correspondência Sumedh Kumar, MBBS, DNB \\ (Orthopaedics), MNAMS, Senior Resident, Room 1218a, Second Floor, \\ Sir Ganga Ram Hospital, New Delhi 110060, Índia \\ (e-mail: Sumedh.4.kumar@gmail.com).
}

\section{Resumo \\ Objetivo A curetagem estendida com adjuvantes de tumores de células gigantes do osso está associada a uma menor taxa de recidiva da neoplasia e à preservação da articulação adjacente. Este estudo foi feito para estimar a taxa de recidiva e o resultado funcional após o uso de plasma de argônio como adjuvante à curetagem estendida. Métodos Cinquenta pacientes com tumores de células gigantes que atendiam a todos os critérios de inclusão foram selecionados para o estudo e submetidos à \\ Palavras-chave \\ - coagulação por plasma de argônio \\ - tumor de células gigantes do osso \\ - neoplasias ósseas \\ - quimiorradioterapia adjuvante \\ - ortopedia curetagem estendida com broca de alta velocidade e fotocoagulação com plasma de argônio entre julho de 2016 e janeiro de 2019. À consulta de acompanhamento, os pacientes foram avaliados quanto a quaisquer queixas de dor e sinais como sensibi- lidade, aumento local da temperatura e diminuição da amplitude de movimento da articulação adjacente. Radiologicamente, os pacientes foram avaliados quanto à presença de qualquer aumento de radiotransparência ao redor do manto de cimento e incorporação do enxerto subarticular. O questionário Musculoskeletal Tumor Society Score (MSTS) foi administrado aos pacientes e a amplitude de movimentação da articulação adjacente foi comparada à articulação contralateral.}

Trabalho desenvolvido no Departamento de Ortopedia, Sir Ganga Ram Hospital, Nova Delhi, Índia.

recebido

12 de Junho de 2021

aceito

22 de Novembro de 2021
DOI https://doi.org/

$10.1055 / \mathrm{s}-0042-1742600$. ISSN 0102-3616. (c) 2022. Sociedade Brasileira de Ortopedia e Traumatologia. All rights reserved.

This is an open access article published by Thieme under the terms of the Creative Commons Attribution-NonDerivative-NonCommercial-License, permitting copying and reproduction so long as the original work is given appropriate credit. Contents may not be used for commercial purposes, or adapted, remixed, transformed or built upon. (https://creativecommons.org/ licenses/by-nc-nd/4.0/)

Thieme Revinter Publicações Ltda., Rua do Matoso 170, Rio de Janeiro, RJ, CEP 20270-135, Brazil 
Resultados Quatro pacientes apresentaram recidiva, o que corresponde a uma taxa de $8 \%$. Seis meses após a cirurgia, 26 de 28 pacientes com tumor no membro inferior tinham capacidade de sustentação de peso de grau 5 e amplitude de movimento comparável à articulação saudável contralateral, com pontuação MSTS média de 27 (intervalo de 18 a 30 ).

Conclusão A curetagem estendida de tumores de células gigantes com coagulação por plasma de argônio está associada a baixas taxas de recidiva da neoplasia; é uma modalidade eficaz no tratamento desses tumores e o resultado funcional é comparável ao do membro saudável.

\section{Abstract}

\section{Keywords}

- argon plasma coagulation

- giant cell tumor of bone

- bone neoplasms

- chemoradiotherapy, adjuvant

- orthopedics
Objective Extended curettage with adjuvants of giant cell tumors of bone is associated with a lower rate of recurrence of the tumor while preserving the adjacent joint. The present study was conducted to estimate the recurrence rate and functional outcome after using argon beam as an adjuvant for extended curettage.

Methods We selected 50 patients with giant cell tumors, meeting all the inclusion criteria, who underwent extended curettage using high speed burr and argon beam photocoagulation between July 2016 to January 2019. On their follow-up visit, they were assessed for any complaints of pain and signs like tenderness, locally raised temperature, and decreased range of motion of the adjacent joint. Radiologically, the patients were assessed for any increased lucency around the cement mantle and uptake of the subarticular graft. Musculoskeletal Tumor Society Score (MSTS) was administered to the patients, and range of motion of the adjacent joint was compared with the contralateral joint.

Results Recurrence was found in 4 patients, that is, an $8 \%$ recurrence rate. Twenty-six out of 28 patients with a tumor in the lower limb had a grade- 5 weight bearing status 6 months from the surgery, and their range of motion was comparable to contralateral healthy joint with an average MSTS score of 27 (18-30).

Conclusion Extended curettage of giant cell tumors using argon beam coagulation is associated with low recurrence rates of the tumor and is an effective modality in the treatment of these tumors besides having a functional outcome comparable to the healthy limb.

\section{Introdução}

O tumor de células gigantes (TCG) do osso foi descrito por Cooper pela primeira vez em 1818. Depois, Nelaton demonstrou sua agressividade local e Virchow descreveu seu potencial maligno. Esses tumores representam cerca de 5\% de todas as neoplasias ósseas primárias. Em sua maioria, os pacientes são adultos com 20 a 40 anos de idade. 0 tumor se estende até o osso articular subcondral ou atinge a cartilagem articular; no entanto, a articulação e/ou sua cápsula raramente são invadidas. ${ }^{1}$ De modo geral, os sintomas são inespecíficos e os pacientes apresentam edema local, calor, e dor que se irradia independentemente da carga. Fraturas patológicas são observadas em aproximadamente 15\% dos casos. $^{2}$ Em radiografias, o TCG é uma lesão lítica pura na região epimetafisária do osso; além disso, pode haver espessamento do osso sobrejacente e adelgaçamento cortical. Normalmente, não há reação perióstea, exceto em caso de ruptura do osso cortical pelo tumor.
O tratamento de escolha na maioria dos TCGs é a curetagem acompanhada por algum método adjuvante e enxerto ósseo. A curetagem simples tem alta taxa de recidiva (30$50 \%$ ), e diferentes adjuvantes foram introduzidos para a redução desses números. Tais adjuvantes, quando associados à curetagem, removem o restante das células neoplásicas, devido a seus efeitos térmicos (nitrogênio líquido, polimetilmetacrilato [PMMA]) ou químicos (fenol, peróxido de hidrogênio, álcool). ${ }^{3}$

Na coagulação por plasma de argônio (APC, na sigla em inglês), o gás argônio fornece plasma de energia térmica para hemostasia e coagulação tecidual; essa energia é distribuída de maneira uniforme com uma sonda para um campo de tecido adjacente. $\mathrm{O}$ gás é ionizado pelos 6.000 volts advindos do fio de tungstênio na ponta da sonda. Esse gás ionizado ou plasma busca o aterramento no tecido mais próximo, com penetração da energia térmica até uma profundidade de cerca de 2 a 3,5 mm. O gás argônio tem ainda a vantagem de ser não-inflamável e relativamente barato. ${ }^{4}$ 
O objetivo deste estudo é avaliar a taxa de recidiva após a curetagem estendida dos tumores ósseos benignos agressivos com uso de plasma de argônio como adjuvante para minimizar essa taxa e melhorar o resultado funcional pósoperatório.

\section{Metodologia}

Esse é um estudo observacional retrospectivo de todos os casos de TCG do osso submetidos à curetagem estendida com APC entre julho de 2016 e janeiro de 2019. Cinquenta pacientes, de ambos os sexos, com 18 anos ou mais e com superfície articular íntegra adjacente ao tumor foram incluídos. Os critérios de exclusão foram a presença de acometimento extenso de partes moles e destruição cortical (violação de mais de $50 \%$ da área do osso cortical que recobre o tumor), ruptura da superfície articular e idade inferior a 18 anos.

Todos os registros dos pacientes, ou seja, achados préoperatórios e intraoperatórios, radiografias antigas e imagens de tomografia computadorizada (TC) e ressonância magnética (RM) foram cuidadosamente revistos. A recidiva do tumor foi avaliada por exame clínico à consulta de acompanhamento e radiografia da área operada. A TC de tórax com contraste foi realizada para avaliação de doença metastática

A cirurgia foi realizada pela mesma equipe cirúrgica e anestésica, com o mesmo protocolo pré e pós-operatório para todos os pacientes. Os pacientes foram operados sob anestesia geral ou raquianestesia, dependendo da decisão do anestesista. A incisão e a dissecção do tecido mole foram planejadas para incluir a realização de biópsia durante a cirurgia definitiva. Após a curetagem completa e remoção do tecido tumoral visível, uma broca de alta velocidade foi usada nas margens da cavidade, exceto na região subarticular; a seguir, a cavidade foi lavada por completo com soro fisiológico. Depois, o equipamento de plasma de argônio foi configurado em 100 watts e as paredes de toda a cavidade foram submetidas à fotocoagulação (-Figura $\mathbf{1}$ ), inclusive a região

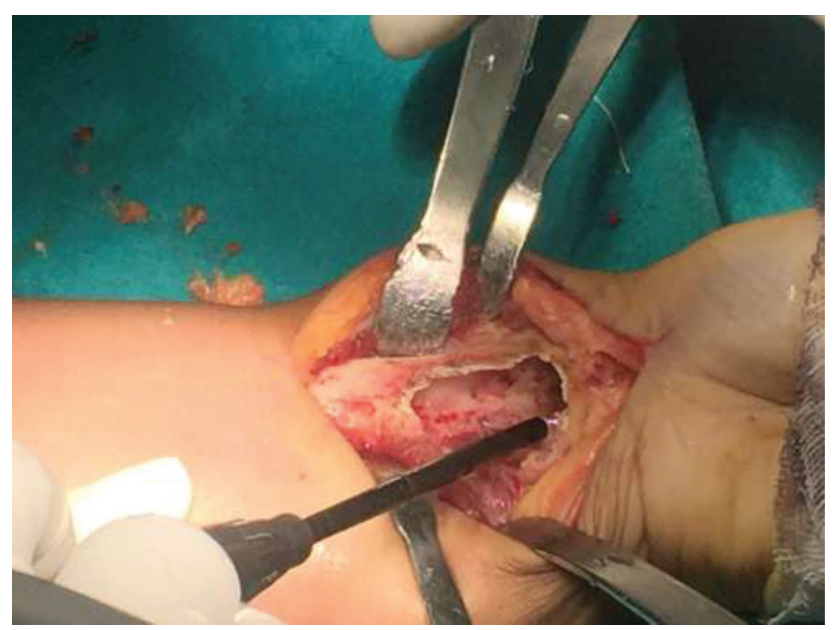

Fig. 1. Fotografia intraoperatória da aplicação do plasma de argônio nas paredes da cavidade curetada em um caso de tumor de células gigantes na porção distal do rádio (esquerda). subarticular, até ficarem enegrecidas. O autoenxerto foi coletado da crista ilíaca e, se necessário, também da fíbula, com o cuidado de usar um novo conjunto de instrumentos para evitar o implante de células tumorais no sítio de enxerto. As hastes corticais da fíbula, assim como enxerto de crista ilíaca, foram utilizadas em caso de presença de uma grande cavidade em quase todo o corte transversal do osso após a curetagem do tumor para aumento da resistência e estabilidade. Um leito do enxerto coletado foi colocado na região subarticular e coberto com Gelfoam. O implante (na maioria dos casos com parafusos esponjosos de rosca parcial e $6,5 \mathrm{~mm}$ ) foi fixado em uma das paredes da cavidade para ancoragem do cimento de PMMA e evitar seu deslocamento. O cimento de PMMA foi preparado e usado no preenchimento da cavidade óssea (-Figura 2 ).

O questionário Musculoskeletal Tumor Society Score (MSTS) foi aplicado em cada um desses pacientes em sua consulta de acompanhamento, dependendo do sítio de acometimento, juntamente com a avaliação da amplitude de movimento e da capacidade de sustentação de peso.

\section{Resultados}

Nesta série de 50 casos, a idade média dos pacientes foi de 28,8 anos, com mediana de 26 anos (-Figura 3). A duração média das queixas no momento da primeira consulta foi de 6,64 meses, com variação de 1 a 18 meses. O TCG estava no fêmur distal em 14 pacientes e na tíbia proximal em 14 pacientes (-Figura 4). O número de casos em homens foi maior, com 36 pacientes do sexo masculino e 14 do sexo feminino. O grau de Campanacci mais observado foi o grau 2, em 22 pacientes. Catorze pacientes apresentavam Campanacci grau 1, e 14 pacientes, grau 3. Quatro pacientes apresentavam recidiva do tumor após tratamento em outro serviço. A recidiva tumoral foi observada em 4 ( $8 \%$ ) pacientes na consulta de acompanhamento. 0 período médio de

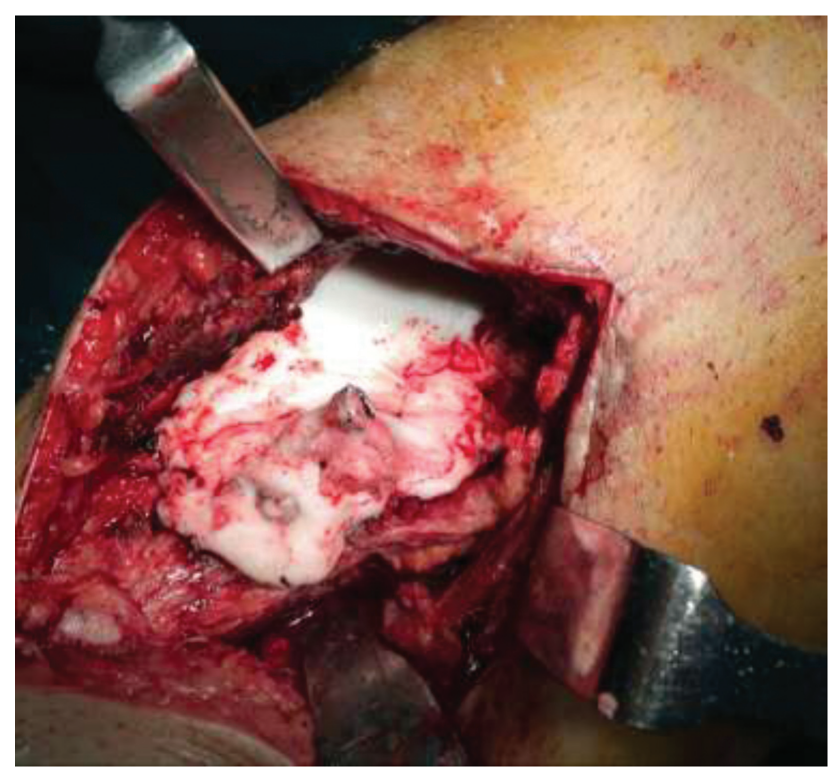

Fig. 2. Aplicação de cimento de polimetilmetacrilato (PMMA) após fixação da cavidade com parafuso esponjoso. 


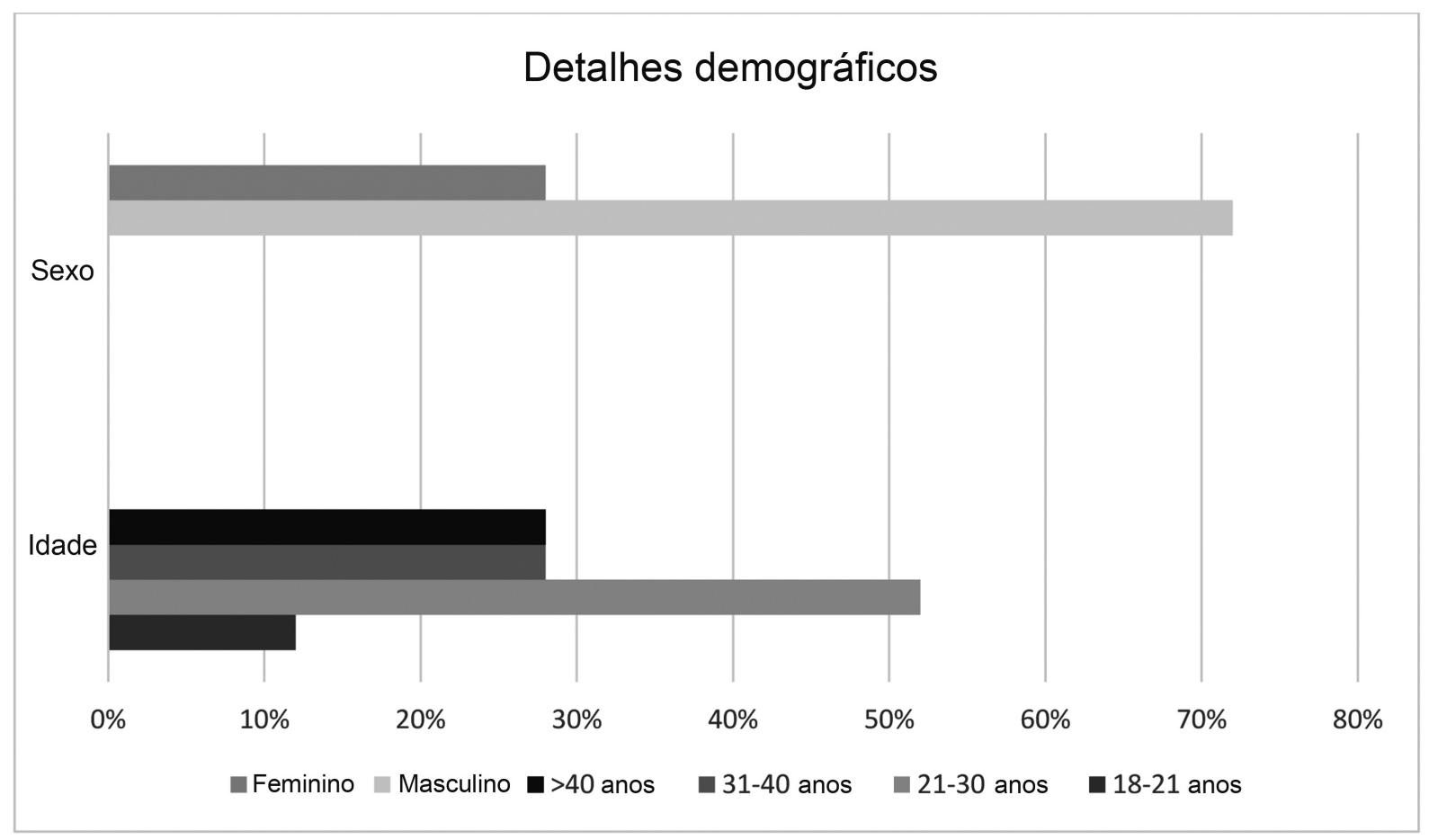

Fig. 3. Detalhes demográficos de pacientes.

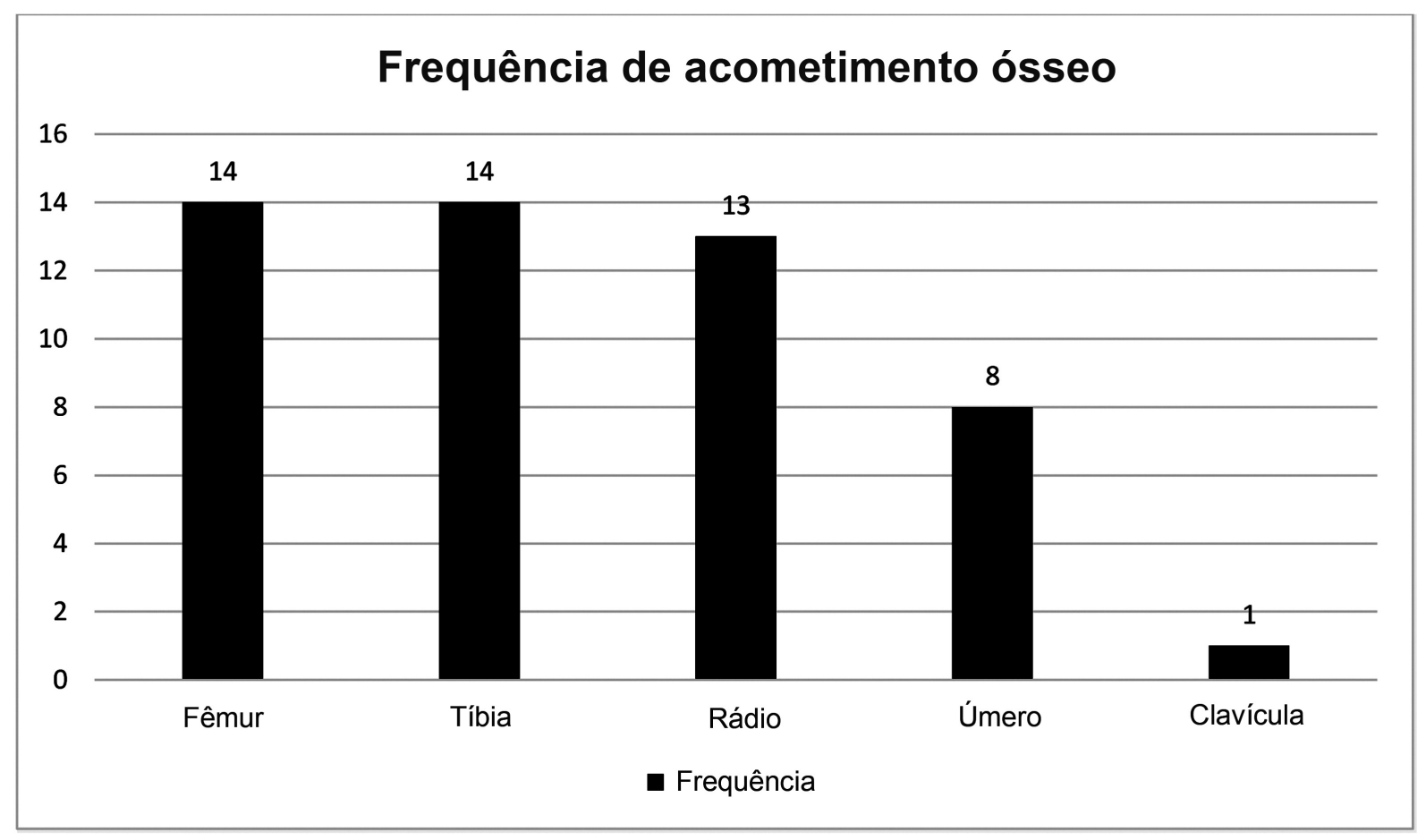

Fig. 4. Frequência do sítio tumoral. 
Tabela 1 Domínios da pontuação do Musculoskeletal Tumor Society Score (MTST) e sua aplicação

\begin{tabular}{|l|l|l|}
\hline $\begin{array}{l}\text { Domínios } \\
\text { comuns } \\
\text { do MSTS }\end{array}$ & $\begin{array}{l}\text { Domínios específicos } \\
\text { ao membro inferior }\end{array}$ & $\begin{array}{l}\text { Domínios específicos } \\
\text { ao membro superior }\end{array}$ \\
\hline $\begin{array}{l}\text { Dor } \\
\text { Função } \\
\text { Aceitação } \\
\text { emocional }\end{array}$ & $\begin{array}{l}\text { Uso de suporte } \\
\text { Capacidade de andar } \\
\text { Marcha }\end{array}$ & $\begin{array}{l}\text { Posição da mão } \\
\text { Destreza } \\
\text { Capacidade de } \\
\text { levantar peso }\end{array}$ \\
\hline \multicolumn{2}{|l|}{$\begin{array}{l}\text { Dependendo do membro acometido, o paciente recebe } 0 \text { a } 5 \\
\text { pontos por cada domínio }\end{array}$} \\
\hline
\end{tabular}

acompanhamento foi de 38 meses (intervalo de 28-58 meses). A pontuação média de MSTS foi de 27 no acompanhamento (intervalo de 18-30) (-Tabela 1).

Os pacientes com TCG em membros inferiores retornaram à deambulação com sustentação de peso 6 meses após a cirurgia. A queixa mais comum no período pós-operatório foi a dor no sítio de enxerto, relatada por 6 dos 50 pacientes; 4 pacientes tiveram infecções superficiais do sítio cirúrgico, e 4 pacientes apresentaram dormência e formigamento na área distal à excisão do tumor (-Tabela 2 ).

\section{Discussão}

As modalidades para o tratamento do TCG são ressecção ampla do tumor com margem de segurança que, de modo geral, sacrifica a articulação adjacente e provoca grave deterioração da qualidade de vida do paciente, ou a curetagem com um método adjuvante. ${ }^{5}$

Em comparação a outros adjuvantes, como o fenol, a APC não está associada a danos nos tecidos moles por derramamento, e sua aplicação na cavidade é relativamente mais fácil. ${ }^{6}$ Complicações, como fraturas intraoperatórias e necrose avascular do osso, são raras e associadas à crioterapia com nitrogênio líquido como adjuvante. ${ }^{7}$ Essas vantagens, além da menor taxa de recidiva, tornam a coagulação por feixe de argônio uma modalidade adjuvante desejável.

Na série atual de 50 pacientes tratados com plasma de argônio como adjuvante, quatro pacientes tiveram uma recidiva detectada na consulta de acompanhamento. Os pacientes foram encaminhados para uma nova cirurgia, com curetagem extensa da área de recidiva e aplicação de PMMA na cavidade após a fotocoagulação por plasma de argônio. Com isso, a taxa de recidiva foi de $8 \%$, comparável às modalidades de outros estudos publicados (-Tabela 3). ${ }^{8-22}$

Quatro pacientes (8\%) apresentaram recidiva dos sintomas após a cirurgia anterior. Após a curetagem estendida com plasma de argônio, nenhum deles apresentou evidências de recidivas na consulta de acompanhamento.

Quatro de nossos pacientes apresentavam comorbidades médicas pré-existentes. Dois pacientes com diabetes desen-
Tabela 2 Complicações da curetagem estendida modificada

\begin{tabular}{|l|l|}
\hline Complicação & Frequência \\
\hline Sítio de enxerto & 6 \\
\hline Infecção superficial & 4 \\
\hline Sintomas neurológicos & 4 \\
\hline Sem complicações & 36 \\
\hline
\end{tabular}

volveram infecções superficiais do sítio cirúrgico. As infecções foram controladas com antibióticos intravenosos e orais, mas prolongaram a internação hospitalar e aumentaram a morbidade. Como parte do nosso procedimento cirúrgico, a colocação do enxerto ósseo na região subarticular para proteção da cartilagem articular foi fundamental em todos os casos. O enxerto ósseo foi retirado da crista ilíaca e/ou da fíbula. O enxerto somente da crista ilíaca foi usado em 34 casos (68\%), apenas de fíbula em dois pacientes (4\%), e de ambos os ossos em 14 pacientes (28\%). O tempo médio de internação foi de 7,76 dias, com máximo de 40 dias e mínimo de 3 dias.

Em termos de recuperação funcional, a pontuação de MSTS foi avaliada em todos os pacientes no acompanhamento, com valor médio de 27 (intervalo de 18-30). Ao exame, todos os pacientes mantinham a amplitude de movimento funcional e eram capazes de realizar suas atividades de vida diária. O cimento de PMMA reduz a recidiva e, junto com o implante, proporciona estabilidade mecânica (-Figure 5). A desvantagem do cimento é a possibilidade de causar danos à cartilagem articular e piorar ainda mais a amplitude de movimento articular. Para evitar isso, um enxerto subarticular espesso foi aplicado para separar a cartilagem articular do cimento ósseo. Isso ajudou a manter a cartilagem articular intacta e protegeu a articulação. 0 enxerto subarticular foi recoberto com Gelfoam para evitar qualquer dano pelo efeito térmico do cimento ósseo. Em última análise, a amplitude de movimento da articulação foi melhor, o que foi significativo e comparável à articulação do lado não acometido ( - Figuras 6 a 8). Isso reduziu o tempo de reabilitação pós-operatória e permitiu ao paciente retomar as atividades diárias logo após a cirurgia. A incorporação do enxerto subarticular foi observada 6 meses após a cirurgia nas radiografias de todos os 50 casos; não houve nenhum caso de reabsorção do enxerto. Em 2018, Wang et al. ${ }^{23}$ relataram que a incorporação do enxerto em uma cavidade curetada levou de 5 a 9 meses. Nossos achados concordam com a literatura existente.

Seis de 50 pacientes (12\%) se queixaram de dor no sítio do enxerto no período pós-operatório imediato. A dor cedeu em 3 a 5 dias com analgésicos. Uma outra queixa dos pacientes foi a formação de cicatriz no sítio do enxerto (-Tabela 3). Nenhum dos pacientes apresentou queixas graves, como hérnia no sítio do enxerto e sintomas sugestivos de meralgia paraestética. Em 1989, Summers B. N. e Eisenstein S. M. conduziram um estudo que revelou dor 
Coagulação por plasma de argônio e curetagem estendida Kumar et al.

Tabela 3 Comparação de diversos estudos e taxas de recidivas de tumor de células gigantes e sua modalidade terapêutica

\begin{tabular}{|c|c|c|c|c|c|c|}
\hline Número & Estudo & Ano & Acompanhamento & Pacientes & Tratamento cirúrgico & Recidivas \\
\hline 1. & McDonald et. al. ${ }^{8}$ & 1986 & 84 meses & 146 & $\begin{array}{l}\text { Ressecção ampla } \\
\text { curetagem + broca }\end{array}$ & $\begin{array}{l}7 \% \\
34 \%\end{array}$ \\
\hline \multirow[t]{3}{*}{2.} & \multirow[t]{3}{*}{ Campanacci et al. ${ }^{9}$} & \multirow[t]{3}{*}{1987} & \multirow[t]{3}{*}{ 2-44 anos } & \multirow[t]{3}{*}{280} & Ressecção ampla & $0 \%$ \\
\hline & & & & & Excisão marginal & $8 \%$ \\
\hline & & & & & Excisão intralesional & $27 \%$ \\
\hline \multirow[t]{2}{*}{3.} & \multirow[t]{2}{*}{ O’Donnel et al. ${ }^{10}$} & \multirow[t]{2}{*}{1994} & \multirow[t]{2}{*}{4 anos } & \multirow[t]{2}{*}{60} & Curetagem + PMMA & $42 \%$ \\
\hline & & & & & Curetagem + PMMA + broca & $17 \%$ \\
\hline 4. & Blackley et al. ${ }^{11}$ & 1999 & 80 meses & 59 & Curetagem + broca & $12 \%$ \\
\hline \multirow[t]{2}{*}{5.} & \multirow[t]{2}{*}{ Trieb et al. ${ }^{6}$} & \multirow[t]{2}{*}{2001} & \multirow[t]{2}{*}{11 anos } & \multirow[t]{2}{*}{47} & Curetagem + broca & $21 \%$ \\
\hline & & & & & Curetagem + broca + fenol & $25 \%$ \\
\hline \multirow[t]{2}{*}{6.} & \multirow[t]{2}{*}{ Turcotte et. al. ${ }^{12}$} & \multirow[t]{2}{*}{2002} & \multirow[t]{2}{*}{60 meses } & \multirow[t]{2}{*}{156} & Ressecção ampla & $16 \%$ \\
\hline & & & & & Curetagem $+\mid$ - broca $+\mid$ - fenol & $18 \%$ \\
\hline 7. & Saiz et al. ${ }^{13}$ & 2004 & 76 meses & 40 & Curetagem + broca + fenol + PMMA & $13 \%$ \\
\hline \multirow[t]{2}{*}{8.} & \multirow[t]{2}{*}{ Su et al. ${ }^{14}$} & \multirow[t]{2}{*}{2004} & \multirow[t]{2}{*}{62 meses } & \multirow[t]{2}{*}{87} & Ressecção ampla & $3 \%$ \\
\hline & & & & & Curetagem + fenol + broca & $18 \%$ \\
\hline 9. & Prosser et al. ${ }^{15}$ & 2005 & 70 meses & 137 & Curetagem + broca & $19 \%$ \\
\hline 10. & Malek et al. $^{16}$ & 2006 & 48 meses & 40 & Curetagem + broca & $33 \%$ \\
\hline 11. & Lewis et al. $^{17}$ & 2007 & 73 meses & 37 & $\begin{array}{l}\text { Curetagem + plasma de argônio + } \\
\text { PMMA }\end{array}$ & $8,3 \%$ \\
\hline \multirow[t]{5}{*}{13.} & \multirow[t]{5}{*}{ Balke et al. $^{18}$} & \multirow[t]{5}{*}{2008} & 60 meses & 214 & Ressecção ampla & $0 \%$ \\
\hline & & & & & Curetagem & $65 \%$ \\
\hline & & & & & Curetagem + broca & $22 \%$ \\
\hline & & & & & Curetagem + PMMA + broca & $18 \%$ \\
\hline & & & & & Curetagem + PMMA + broca $+\mathrm{H}_{2} \mathrm{O}_{2}$ & $12 \%$ \\
\hline 14. & Kivioja et al. ${ }^{19}$ & 2008 & 5 anos & 294 & Excisão ampla/ marginal & $12 \%$ \\
\hline & & & & & Curetagem & $51 \%$ \\
\hline & & & & & Curetagem + PMMA & $23 \%$ \\
\hline 15. & Errani et al. ${ }^{20}$ & 2010 & 91 meses & 349 & Ressecção ampla & $12 \%$ \\
\hline & & & & & Curetagem + broca + fenol & $51 \%$ \\
\hline & & & & & Curetagem + broca + fenol + PMMA & $22 \%$ \\
\hline 16. & Klenke et al. ${ }^{21}$ & 2011 & 108 meses & 118 & Ressecção ampla & $5 \%$ \\
\hline & & & & & Curetagem + broca & $32 \%$ \\
\hline & & & & & Curetagem + fenol + broca & $34 \%$ \\
\hline & & & & & Curetagem +PMMA + broca + fenol & $15 \%$ \\
\hline 17. & Benevenia et al. ${ }^{22}$ & 2012 & 10 meses & 93 & Curetagem + fenol & $17,1 \%$ \\
\hline & & & & & Curetagem + plasma de argônio & $14,8 \%$ \\
\hline
\end{tabular}

Abreviaturas: PMMA, Polimetilmetacrilato; $\mathrm{H}_{2} \mathrm{O}_{2}$, peróxido de hidrogênio. 

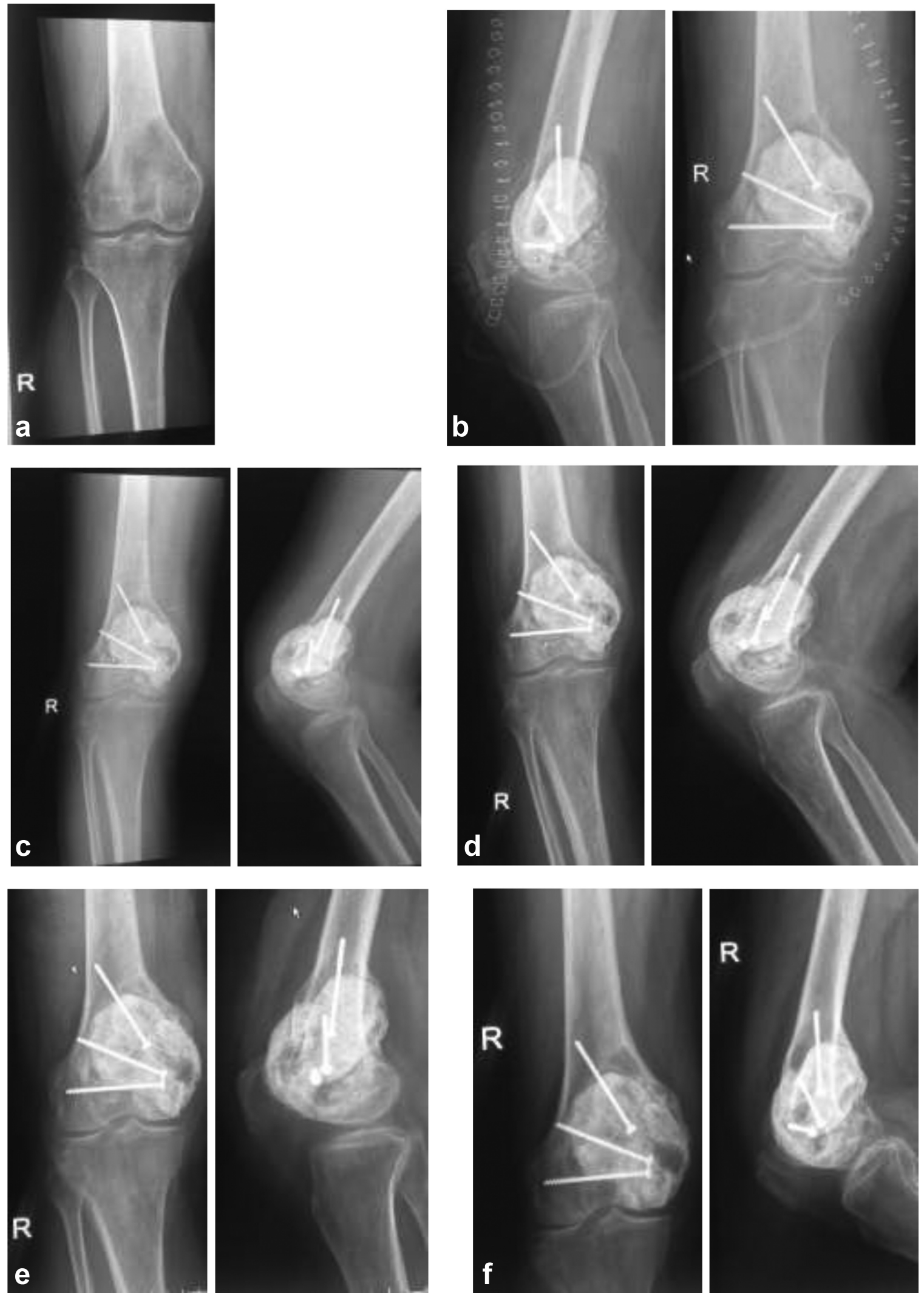

Fig. 5 a-f Radiografias de paciente com tumor de células gigantes na porção distal do fêmur. (a) Radiografia pré-operatória. (b) Radiografia no período pós-operatório imediato. (c) Radiografia 1 mês após a cirurgia. (d) Radiografia 3 meses após a cirurgia. (e) Radiografia 6 meses após a cirurgia. (f) Fotos clínicas na consulta de acompanhamento sugestivas de recidiva. 

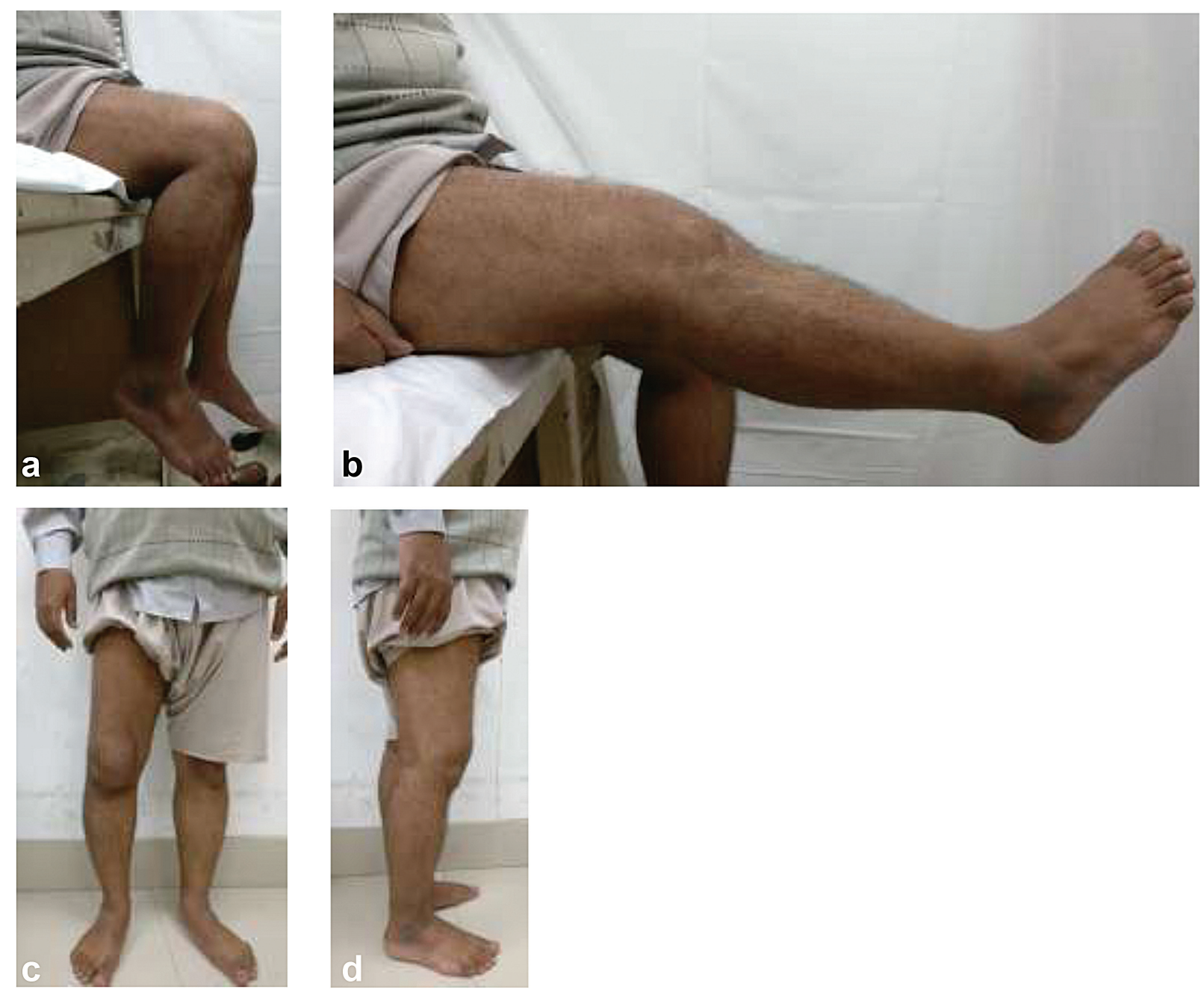

Fig. 6 a-d Imagens clínicas mostrando amplitude de movimento à consulta de acompanhamento. (a) Flexão do joelho. (Extensão do joelho). - Fig 6 c, d. Sustentação de peso sem assistência.

"significativa" no sítio doador em $25 \%$ dos pacientes, dor "aceitável" em $24 \%$, e nenhuma dor em $51 \%$ dos pacientes submetidos à retirada de enxertos ósseos da crista ilíaca. 0 motivo para a redução significativa da morbidade do sítio do enxerto foi a técnica cirúrgica de coleta de um enxerto bicortical da crista ilíaca em comparação a um enxerto ósseo tricortical; além disso, deixamos a porção interna da crista ilíaca intacta e fechamos a ferida cirúrgica em planos e sem tensão. Quatro dos 50 pacientes (8\%) desenvolveram infecção superficial do sítio cirúrgico que se manifestou como eritema e endurecimento ao redor das suturas no segundo dia pós-operatório. Antibióticos intravenosos e curativos regulares levaram à resolução completa da infecção até o $5^{\circ}$ dia pós-operatório. Todos os pacientes que desenvolveram infecções eram diabéticos. Quatro (8\%) pacientes de nosso estudo queixaram-se de formigamento e dormência na área distal ao tumor no período pós-operatório. Esses pacientes apresentaram tumor no côndilo medial do fêmur distal. As queixas diminuíram com o tratamento oral com neuromoduladores, como a gabapen- tina. Takeuchi et al. ${ }^{24}$ publicaram um estudo em 2018 com 26 pacientes acompanhados por pelo menos 36 meses em que relataram um caso de osteoartrite, um caso de sinovite crônica, e uma fratura (3,8\% cada), que foram tratadas de forma conservadora.

\section{Conclusão}

O presente estudo revisou os dados de 50 pacientes submetidos à curetagem estendida com broca de alta velocidade, fotocoagulação por plasma de argônio e cimento de PMMA. A taxa de recidiva do tumor foi de $8 \%$, com bom resultado funcional, já que a articulação adjacente foi poupada. Essa taxa de recidiva foi uma das menores já descrita na literatura. Apesar do pequeno tamanho da amostra, nosso estudo ainda permite inferir que a combinação da fotocoagulação por plasma de argônio e curetagem estendida é uma modalidade eficaz para o tratamento de TCGs e está associada a uma taxa significativamente menor de recidiva. Sua precisão, facilidade de uso e baixo índice de 

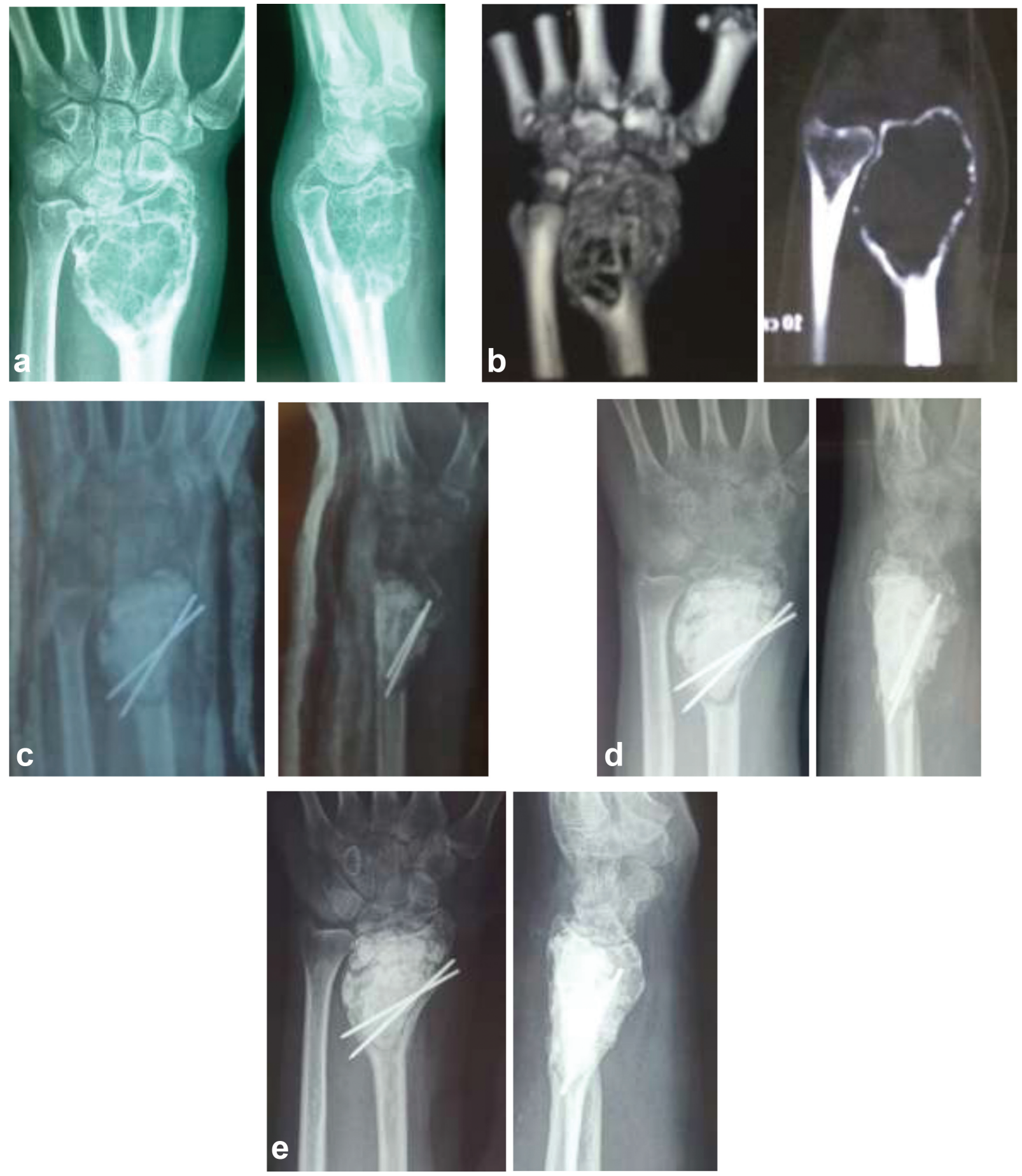

Fig. 7 a-e Radiografias de paciente com tumor de células gigantes na porção distal do rádio. (a) Radiografia pré-operatória. (b) Tomografia computadorizada pré-operatória. (c) Radiografia no período pós-operatório imediato. (d) Radiografia 3 meses após a cirurgia. (e) Fotos clínicas na consulta de acompanhamento. 


\section{Coagulação por plasma de argônio e curetagem estendida Kumar et al.}
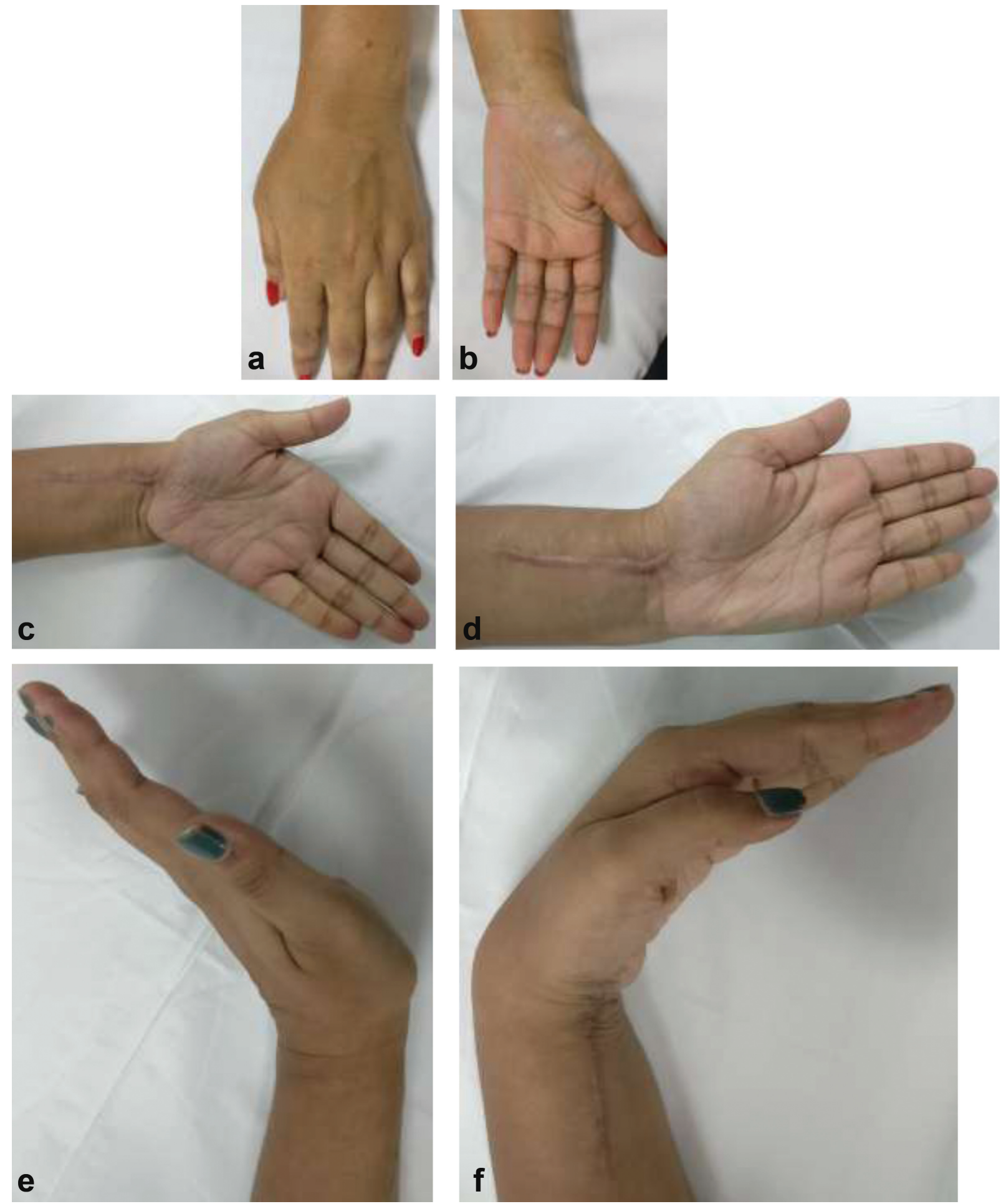

Fig. 8 a-f Fotos clínicas de paciente com tumor de células gigantes do rádio distal. (a) Imagens clínicas pré-operatórias. (f) Fotos clínicas na consulta de acompanhamento. 
complicações o tornam uma valiosa alternativa de tratamento adjuvante.

\section{Suporte Financeiro}

Este estudo não recebeu suporte financeiro de fontes públicas, comerciais ou sem fins lucrativos.

\section{Conflito de Interesses}

Os autores declaram que não há conflito de interesses.

\section{Referências}

1 Sobti A, Agrawal P, Agarwala S, Agarwal M. Giant Cell Tumor of Bone - An Overview. Arch Bone Jt Surg 2016;4(01):2-9

2 Dreinhöfer KE, Rydholm A, Bauer HC, Kreicbergs A. Giant-cell tumours with fracture at diagnosis. Curettage and acrylic cementing in ten cases. J Bone Joint Surg Br 1995;77(02):189-193

3 Campanacci M. Giant-cell tumor and chondrosarcomas: grading, treatment and results (studies of 209 and 131 cases). Recent Results Cancer Res 1976;(54):257-261

4 Cohen J, Abedi M, Haber G, et al. Argon plasma coagulation: a new effective technique of non-contact thermal coagulation. Experience in 44 cases of GI angiomata. Gastrointest Endosc 1996;43:293

5 Schajowicz F. Giant-Cell Tumor (Osteoclastoma). In: Tumors and Tumorlike Lesions of Bone and Joints. New York: Springer; 1981: 301-367

6 Trieb K, Bitzan P, Lang S, Dominkus M, Kotz R. Recurrence of curetted and bone-grafted giant-cell tumours with and without adjuvant phenol therapy. Eur J Surg Oncol 2001;27(02):200-202

7 Malawer MM, Bickels J, Meller I, Buch RG, Henshaw RM, Kollender Y. Cryosurgery in the treatment of giant cell tumor. A long-term followup study. Clin Orthop Relat Res 1999;(359): 176-188

8 McDonald DJ, Sim FH, McLeod RA, Dahlin DC. Giant-cell tumor of bone. J Bone Joint Surg Am 1986;68(02):235-242

9 Campanacci M, Baldini N, Boriani S, Sudanese A. Giant-cell tumor of bone. J Bone Joint Surg Am 1987;69(01):106-114

10 O'Donnell RJ, Springfield DS, Motwani HK, Ready JE, Gebhardt MC, Mankin HJ. Recurrence of giant-cell tumors of the long bones after curettage and packing with cement. J Bone Joint Surg Am 1994;76 (12):1827-1833

11 Blackley HR, Wunder JS, Davis AM, White LM, Kandel R, Bell RS. Treatment of giant-cell tumors of long bones with curettage and bone-grafting. J Bone Joint Surg Am 1999;81(06):811-820
12 Turcotte RE, Wunder JS, Isler MH, et al; Canadian Sarcoma Group. Giant cell tumor of long bone: a Canadian Sarcoma Group study. Clin Orthop Relat Res 2002;(397):248-258

13 Saiz P, Virkus W, Piasecki P, Templeton A, Shott S, Gitelis S. Results of giant cell tumor of bone treated with intralesional excision. Clin Orthop Relat Res 2004;(424):221-226

14 Su YP, Chen WM, Chen TH. Giant-cell tumors of bone: an analysis of 87 cases. Int Orthop 2004;28(04):239-243

15 Prosser GH, Baloch KG, Tillman RM, Carter SR, Grimer RJ. Does curettage without adjuvant therapy provide low recurrence rates in giant-cell tumors of bone? Clin Orthop Relat Res 2005;(435): 211-218

16 Malek F, Krueger P, Hatmi ZN, Malayeri AA, Faezipour H, O'Donnell RJ. Local control of long bone giant cell tumour using curettage, burring and bone grafting without adjuvant therapy. Int Orthop 2006;30(06):495-498

17 Lewis VO, Wei A, Mendoza T, Primus F, Peabody T, Simon MA. Argon beam coagulation as an adjuvant for local control of giant cell tumor. Clin Orthop Relat Res 2007;454(454): 192-197

18 Balke M, Schremper L, Gebert C, et al. Giant cell tumor of bone: treatment and outcome of 214 cases. J Cancer Res Clin Oncol 2008;134(09):969-978

19 Kivioja AH, Blomqvist C, Hietaniemi K, et al. Cement is recommended in intralesional surgery of giant cell tumors: a Scandinavian Sarcoma Group study of 294 patients followed for a median time of 5 years. Acta Orthop 2008;79(01):86-93

20 Errani C, Ruggieri P, Asenzio MA, et al. Giant cell tumor of the extremity: A review of 349 cases from a single institution. Cancer Treat Rev 2010;36(01):1-7

21 Klenke FM, Wenger DE, Inwards CY, Rose PS, Sim FH. Giant cell tumor of bone: risk factors for recurrence. Clin Orthop Relat Res 2011;469(02):591-599

22 Benevenia J, Patterson FR, Beebe KS, Abdelshahed MM, Uglialoro AD. Comparison of phenol and argon beam coagulation as adjuvant therapies in the treatment of stage 2 and 3 benign-aggressive bone tumors. Orthopedics 2012;35(03):e371-e378

23 Wang YL, Min L, Duan H, et al. [Therapeutic Effect of Uncemented Allograft-prosthetic Composite for the Reconstruction of Tumorous Bone Defect]. Sichuan Da Xue Xue Bao Yi Xue Ban 2018;49 (01):129-132

24 Takeuchi A, Suwanpramote P, Yamamoto N, et al. Mid- to longterm clinical outcome of giant cell tumor of bone treated with calcium phosphate cement following thorough curettage and phenolization. J Surg Oncol 2018;117(06):1232-1238 